\title{
An Empirical Investigation among Iranian Consumers with Variety Consumption Habits in Cosmetic Sector
}

\author{
Alireza Miremadi ${ }^{1}$, Shirin Ranjbar Toutoue ${ }^{1} \&$ Rosa Mozaffari Oghani ${ }^{1}$ \\ ${ }^{1}$ Sharif University of Technology—International Campus, Iran \\ Correspondence: Dr. Alireza Miremadi, Marketing Professsor \& Head of Department at Sharif University of \\ Technology-International Campus, Iran. Tel: 98-913-315-2401. E-mail: ar.miremadi@sharif.edu or \\ alireza.miremadi@gmail.com
}

Received: December 13, 2012

Accepted: March 8, 2013 Online Published: April 16, 2013

doi:10.5539/ijms.v5n3p133

URL: http://dx.doi.org/10.5539/ijms.v5n3p133

\begin{abstract}
This paper is the first paper that provides an in-depth discussion on the scientific methodologies that can be used to measure and Key Factors That Influence on Consumer Consumption and Converting them to loyal customer and various promotional activities in Iranian cosmetic product first of all, this paper reviews the history cosmetic industry, current status of e-purchasing and influence of culture on domestic and foreign cosmetic products in Iran.This exploratory study sought to answer four sections related about understanding the consumer buying behaviour in cosmetic product in Iranian market concentrated on domestic and foreign shampoo such as Determining key factors that influence on consumer consumption and converting them to loyal customer in Iranian cosmetic market, Influence of various promotional activities in cosmetic product, E- tailing or electronic buying attractiveness, Critical Factors influence on Consumer Buying Behaviour and Attitudes towards Cosmetic Product.We have initiated with exploratory research and gradually shifted to descriptive research. The instruction method for collecting the primary data was questionnaire. In this research, a modelling framework is developed for Marketers and their companies to deal with promotional and advertising budget constraints, therefore selecting the precise promotional mix or integrated marketing communication (IMC) is valuable asset and equip companies to penetrate and develop the market share in Iranian market in this competitive market accordingly.Empirical studies have shown that the Quality, product reliability (genuine), package and variety of distribution channels are the most influential factors for customers' satisfaction and consumer buying behaviour about the foreign cosmetic product (shampoos), while quality, product reliability (genuine), package, meet the requirements and variety of distribution channels are the most influential factors for customers' satisfaction and consumer buying behaviour in domestic Iranian product.
\end{abstract}

Keywords: consumer behaviour, e-buying, promotional activities, brand, cosmetic product, model, market share, USP, marketing strategy, Iran

\section{Introduction}

Cosmetics have been around for thousands of years. When people hear the word cosmetics, they tend to think of makeup and perfume designed for women. Cosmetics actually come in many forms, ranging from powders, body makeup, soap, shampoo and toothpaste (Sameer Kumar, Cindy Massie et al.). The use of cosmetics fragrances and personal care products can be traced back to ancient times as early as Egyptian, Greek and Roman eras,when people painted their body for religious ceremonies, war, and rituals and each Makeup tattoos and adornments conveyed necessary social information (DeBrohun). Besides, archaeological studies made in Iran indicate that history of use of cosmetics is traced back to 10,000 years ago and it wasn't limited to women only but men also used it as a religious belief and improving their beauty. Iranian women and men for example were used to apply red and yellow colors a cosmetic to paint them 5000 B.C. Greeks also have praised Achaemenians habit of using cosmetics and attribute such use of cosmetics and perfume to eastern people (Godlove 2011).

Marketers by analysingthe cosmetic's consumer gain market share, sales increase and maintain strong and continuous growth, by identifying consumers' thoughts and behaviour. marketers can begin to understand how they choose specific cosmetic products and brand ultimately (Michelle Guthrie 2008). This allows cosmetics companies to compete more effectively and to enhance current marketing strategies, some of tools which can help in this area is use from promotional tools and techniques and considering the effectiveness of each tools in 
the market, advertising is an essential marketing tools that helps create brand awareness and brand loyalty. Advertising is a paid, mass-mediated attempt to persuade. advertising is part of IBP (integrated brand promotion) which we like to consider some of its tools in our research, in brief, IBP is the process of using a wide range of promotional tools working together to create widespread brand exposure (Thomas C.O'Guinn 2009). Estimated over 70,000,000 individuals for Iran's population, which $50 \%$ of people are under 25 year old, so with such large number of young population (leung 2011), Iran has been ranked as $1^{\text {st }}$ and $7^{\text {th }}$ in the Middle East and world respectively (2010) which consuming cosmetics and hygienic materials, for instance Iranian's people has brought about yearly 820 million shampoos in a year (The world Marketing News 2011). Such immoderate consumption of this product among Iranians could be an interesting drive to analyse its consumer buyingbehaviour.

\section{Research Objectives}

The researcher divided the questions in four parts for consumer buying behavior and influence of promotional activities on cosmetic and hygienic sector among the Iranian respondents.

Part A: Determining Key Factors That Influence on Consumer Consumption and Converting Them to Loyal Customer in Iranian Cosmetic Market.

Part B: Influence of Various Promotional Activities in Cosmetic Product

Various promotional strategies that may influence the product advertising in accordance with customer's perception have been investigated in the present study. Customers are then asked to identify those promotional strategies, so that two following issues could be explored in detail;

Part C: E- Tailing or Electronic Buying Attractiveness

Analysis of e-buying and evaluation of existing barriers in this field of activity based on the customer's perception is major issue in Iranian market.

Part D: Critical Factors influence on Consumer Buying Behaviour and Attitudes towards Cosmetic Product

\section{Literature Review}

At present, research activities in the area of consumer buying behaviour, effectiveness of promotional activities and the influence of website attractiveness in cosmetic products are very limited among the Iranian respondents. First of all, we considered the nature of shampoo, it`s origin and Iranian use to remove dirt in past and the first company which introduced the shampoo in Iranian industry, then we consider electronic purchasing as new method of buying cosmetic product (shampoo) in Iranian market, later on, we discover the critical element that influence on consumer buying behaviour which is known as culture and its impact on usage of cosmetic products both domestic and foreign brands.

\subsection{Definition and History of Shampoo}

Shampoo is a hair care product used for removal of oils, dirt, skin particles, dandruff, environmental pollutants and other contaminant particles that gradually build up in hair (2009).

The word shampoo in English is derived from Hindustani Champoo and dates to 1762- the shampoo itself originated in the eastern regions of the Mughal Empire particularly in the Nawab of the Bengal where it is introduced as a head massage, usually consisting of alkali, natural oils and fragrances. Shampoo was first introduced in Britain by a Bihari Muslim entrepreneur named Sake Dean Mohamed (2009). Years before emergence of modern Shampoo,Iranians used to apply herbal stuff such as cedar, Choubak, minerals (mineral soils) for washing their hair (Amadzadeh 2009). As the first hygienic and cosmetic production unit in Iran, Darougar Corporation has operated over 75 years and it has more than 13 active units producing Shampoo (2011).

\subsection{Current Status of E-Purchase in Iran}

Based on published reports, there are 7500 e-shops which have contracted with Ian Post Office that do not include e-services and domain sales shops (Raouf 2009). As revealed through detailed studies in this regard, around 60\% of such e-shops fail to accomplish their mission and accordingly $70 \%$ of people look up the shop website will not refer to it again that would bring about low visit rate of such websites (2010). Major failure causes of e-commerce shops in Iran (2010):

\footnotetext{
$\checkmark \quad$ Managerial malfunction and lack of proper required infrastructure,

$\checkmark$ Unreliability of e-commerce shops based on customers' viewpoints,
} 
$\checkmark$ Lack of consistency between IT required and managerial knowledge in constructing an e-commerce shop,

$\checkmark \quad$ Inadequate promotional activities,

$\checkmark \quad$ Lack of utilization from proper competitive prices as a vital motivating factor,

$\checkmark \quad$ combine the delivery fee included in main price.

Main causes of customers' reluctances toward e-buying and influencing factors in their acquaintances with company's website based on customers' viewpoints (Xavier 2011). Most of the influencing factors in customers' reluctances toward e-buying could be ranked as follow in accordance with their viewpoints;

$>$ Lack of reliable and credible websites for e-buying,

$>$ Lack of accountability for receives complaints and responsibility against customers questions,

$>$ Lack of certainty about product warranty,

$>$ Continued existence of economic sanctions against Iran and accordingly block the products imported product toward the country.

As depicted in the graph above, major product visit in the website is made randomly during surfing the net. Other criteria could be stated suggestions made by friends and introducing the company in products' brochures that might be known as worse influencing factors in customers' perception of the website that indicates the lack of adequate knowledge of advertising methods toward customer's awareness and perceptions. Despite the importance of increasing trend of cosmetic consumption in Iran, there has been no comprehensive research in this regard, and the present study could be regarded as the first investigation into such field.

\subsection{Culture and Herbal Perspective}

culture infuses, works on, is part of, and generally lands on all consumption and it affects every aspect of human behaviour, including consumer behaviour and advertising infect when advertisers spend time and money studying just why consumers consume certain goods and services, or why they consume them in a certain way, they are considering culture. Hofstede defines culture as often intangible and used to distinguish one group, organization or nation from another (Russel 2006). Values are the defining expression of culture, values express in words and deeds what is important to culture, values are cultured bed rock, values are enduring. They cannot be changed quickly or easily, they are thus different from attitudes, which can be changed through quickly or easily. They are thus different from attitude which can be changed through a single advertising campaign or even a single advertising, the figure1 illustrate this relationship (Thomas C.O'Guinn 2009).

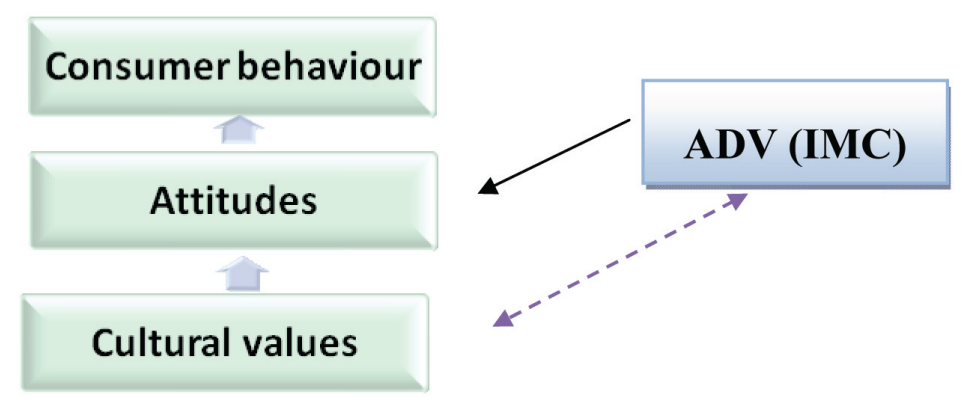

Figure 1. Culture \& consumer behaviour model (Thomas C.O`Guinn 2009)

Values are the foundation of this structure. Attitudes are, in turn influenced by values, as well as by many other sources. Advertising has to be consistent with, but cannot easily or quickly change, values it is thus senseless for an advertiser to speak of using advertising to change values in any substantive way, advertising influence very slowly and through cumulative impact, over years and years. It is also the case that cultural values change advertisements (Thomas C.O’Guinn 2009).

\subsection{Culture from Advance Technology Perspective}

A clear understanding of consumer behaviour helps companies to aim for the right target customers and make successful marketing strategies in order to offer their products, due to the fact that consumer change, it is crucial to understand consumer behaviour (Jobber 2009), for instance, consumer behaviour may be affected by many factors 
like culture, this factor can also be affected by other factors such as development of technology, with respect to the globalization, an expansion of accessory to media (specially satellite dish and internet in Iran) the new life style, new fashion are available to everyone. In the view of this topic and considering an innate desire to be beauty, we can see the growing of person's tendency to be trendy and consume the product's that introduced by media that result in increasing of demand for foreign brands, but we must be mentioned that inter-cultural differences will still exist and have a great impact on company's marketing strategies (Russel 2006).

\section{Research Methodology}

This exploratory study sought to answer four sections related about understanding the consumer buying behaviour in cosmetic product in Iranian market concentrated on domestic and foreign shampoo. We have developed our questionnaire in four parts.

$>$ Determining key factors that influence on consumer consumption and converting them to loyal customer in Iranian cosmetic market.

$>$ Influence of various promotional activities in cosmetic product.

$>$ E- tailing or electronic buying attractiveness.

$>$ Critical Factors influence on Consumer Buying Behaviour and Attitudes towards Cosmetic Product.

As we illustrated in figure 2, we have initiated with exploratory research and gradually shifted to descriptive research. The instruction method for collecting the primary data was questionnaire. The questionnaire is just designed with 61 questions (we conduct pilot testing in order to studying the respondent's perception from question, that there were not any ambiguous to them). The five point likert scale was used to measure the consumer response from 1 indicates very poor and 5 indicates very good. The strategy of this article is survey and case study, that we achieve it by conducting convenience sampling.

Through the process of data collection, first we interview people to measure the quality of questionnaire in order to find that to what extent our respondents understand our purpose and measurement of our questionnaire reliability.

The methods of interview and drops off/pick up, both used for data gathering (primary \&secondary data), in addition we use five points Likert-scale in our questionnaire.

According to Fisher (2007) the number of distributed questionnaire will have to be larger than the minimum required and the response rate of $30 \%$ is considered very good, in this study 470 questionnaire were distributed and approximately $100 \%$ response rate provided.

Because we discussed with the people and submitted then submitted the questionnaire in hand and taken back after filling up by them. 


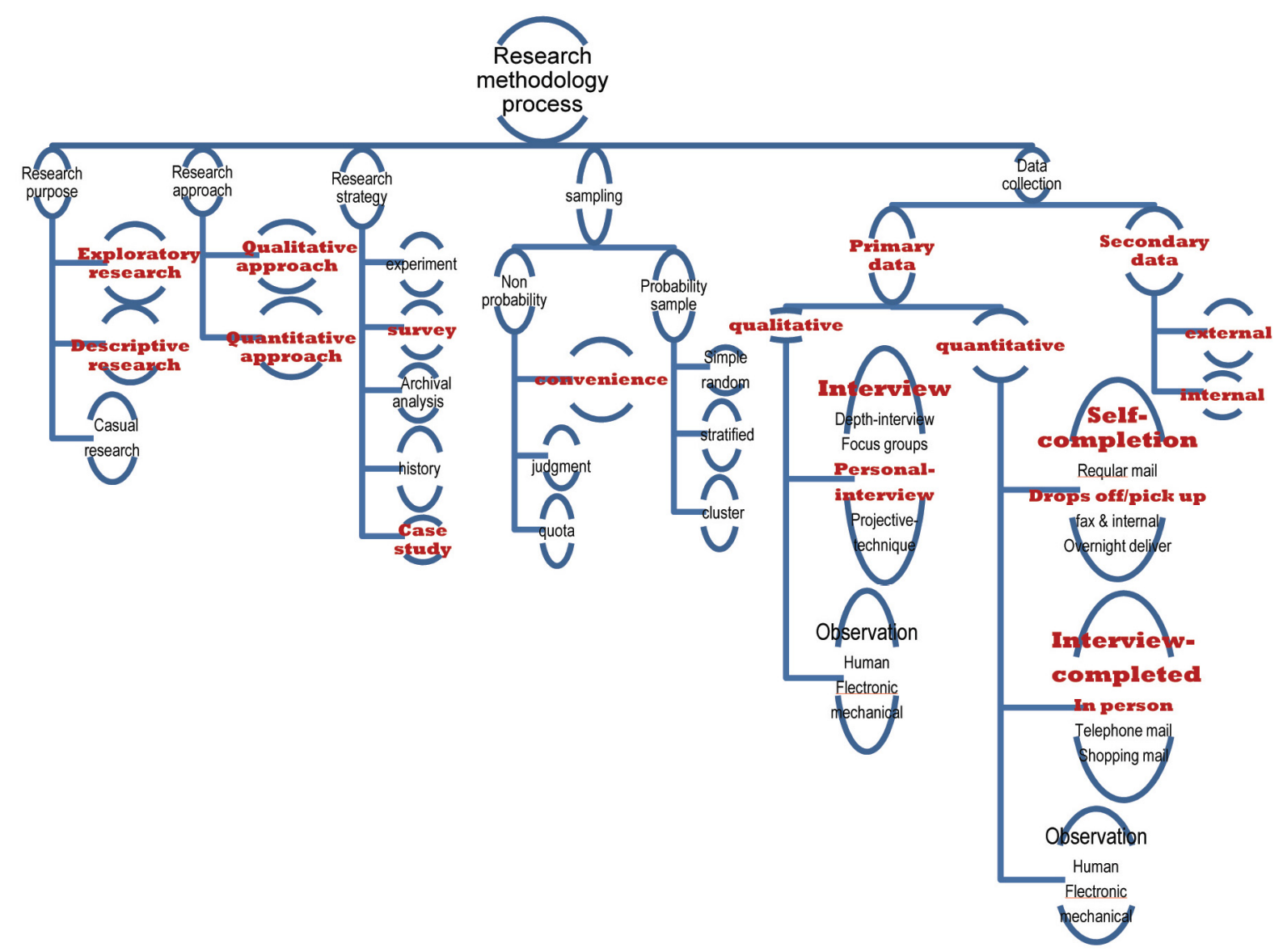

Figure 2. Research methodology process (Alireza Miremadi, 2011)

\subsection{Sampling Size Calculation}

There were 70 questionnaire distributed randomly among people for evaluation of sample size that achieved using $\sigma$ and error estimation of 0.1 under $95 \%$ certainty level in the following formula;

$$
\left(\frac{\sigma \times \frac{z \alpha}{2}}{e}\right)^{2}=467 \text { (sample size) }
$$

$e=0.1, \frac{z x}{2}=1.96$

470 questionnaires then distributed randomly in 4 major cities (Tehran, Mashhad, Kerman and Hormozgan). we take advantage ofgamma coefficient indicator to discover percentage of dependency between each pairs in part A, C. The Gamma Coefficient is realized through balancing coherent pairs and reverses ones. If number of reverse pairs is the same, there would be no specific relation between two variables; otherwise there would be positive correlation (Greater number of coherent pairs) or negative correlation (M. Momeni 2009).

\subsection{Measurement}

Our questionnaire is divided into five sections. In section one, respondents were asked to answer some descriptive information about themselves such as, education, gender, income range, and the types of shampoo, duration of usage, purchase frequency they had used. In section two and three, four, a set of questions were designed to evaluate variables related to our hypothesis. In this section all questions had five point Likert scale responses. The respondents were asked to reflect the extent of influence of variables on the measured variable from very high to very low. In the last section, there was multiple choice questions which respondents were asked to measure the effectiveness of E-tailing and web attractiveness. 


\subsection{Evaluating Measurement Scale}

Internal consistency or reliability of the instrument was conducted by finding the Cronbach alpha coefficient. Cronbach's alpha is an index of reliability associated with calculating the reliability of items that are not scored right versus wrong (Wallen 2003). As depict in figure 3 the ranges of Alpha coefficient is from 0 to 1 and it may be used to describe the reliability of factors obtained from multi-point formatted questionnaires or scales (i.e., rating scale: $1=$ very low, $5=$ very high) (Wallen 2003). The higher the score, the more reliable the scale is. The researchers reached on 0.711 for Alpha Cronbach which is higher than what Nunnery indicated as an acceptable reliability coefficient.

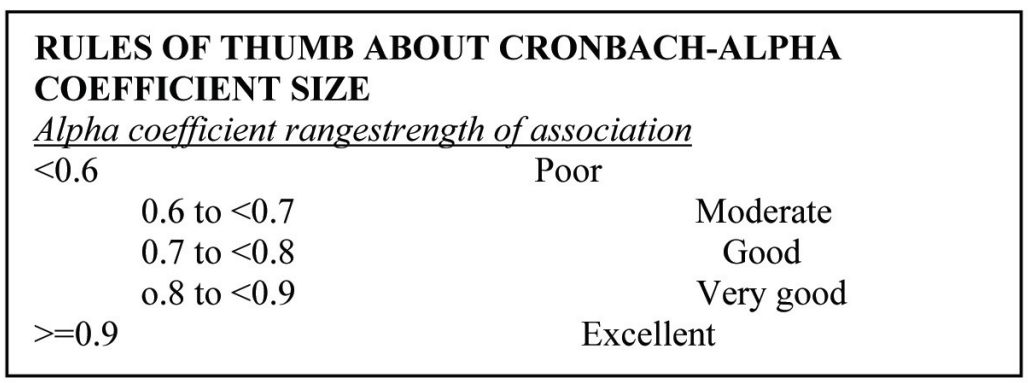

Figure 3. Rules of thumb about Cronbach`s Alpha coefficient size (Joseph F. Hair, Arthor H. Money et al. 2007)

Table 1. Internal consistency for promotion technique

\begin{tabular}{lll}
\hline Variable & Questions & Cronbach`s Alpha \\
\hline Promotion Technique & Q20 to q32 & 0.902 \\
Satisfaction & Q10,q11,q12,q34 to q39,q41,q44 & 0.781 \\
Website Satisfaction & Q50 to q57 & 0.871 \\
Website Attractiveness & Q58,q59 & 0.747 \\
\hline
\end{tabular}

As stated in table 1, reliability of investigation queries has been accepted because of $\alpha>0.7$. So results and findings of the study could be relied upon and used for further investigations. Validity is the extent to which a construct measures what it is supposed to measure. To assess measurement of validity is done through factor analysis and face validity (Joseph F. Hair, Arthor H. Money et al. 2007). To illustrate content validity or face validity, we conducted interviews with marketing professionals in companies to validate the items and variable which are extracted from related literature and to find new items that are used in Iranian market. Furthermore, after collecting data from interviews, we consulted with marketing professors to verify the factors and variables which are extracted. Then, questionnaire was prepared based on the gathered data, after that their ideas and comments about the questions were collected.

Table 2. K-S test results in line with analysis of study normality test

\begin{tabular}{lllll}
\hline factors & Promotion technique & satisfaction & Website satisfaction & Website attractiveness \\
Number & 465 & 470 & 169 & 185 \\
Normal parameters & & & & \\
mean & 38.98 & 36.21 & 6.49 & 24.27 \\
std. Deviation & 16.89 & 9.38 & 1.89 & 8.13 \\
Asymp.sig(2-tailed) & .000 & .000 & .001 & .005 \\
\hline
\end{tabular}

With referring to table 2 , the $\mathrm{p}$ value $<0.05$ and in the same way all factors analyzed here do not comply with normal distribution.

\section{Data Analysis and Interpretation}

Part A: Determining key factors that influence on consumer consumption and converting them to loyal customer in Iranian cosmetic market.

K-2 test has been utilized in the following assumptions due to qualitative nature of factors investigated in the 
study by researcher.

1.a The association between consumption of a product and customer's satisfaction.

1.b The relationship between duration of consumption and customer buying decision concerning further consumption of that product.

1.c What is the impact of sales agents' behaviour on the consumer buying decision to keep on using the unique brand?

Table 3. Chi-square test for the measuring the association among the variables

\begin{tabular}{lllllll}
\hline & \multicolumn{2}{l}{ Hypothesis 1.a } & \multicolumn{2}{l}{ Hypothesis 1.b } & \multicolumn{2}{l}{ Hypothesis 1.c } \\
\hline variable & $\mathrm{Q}^{2}$ & satisfaction & Q44 & Q5 & Q44 & Q16 \\
Chi-square & $287.892^{\mathrm{a}}$ & $488.315^{\mathrm{b}}$ & $59.485^{\mathrm{a}}$ & $287.892^{\mathrm{b}}$ & $287.892^{\mathrm{a}}$ & $236.649^{\mathrm{b}}$ \\
$\mathrm{df}$ & 4 & 48 & 3 & 4 & 4 & 4 \\
Asymp.sig & .000 & .000 & .000 & .000 & .000 & .000 \\
Test result & $\mathrm{H}_{0}$ NOT accepted & \multicolumn{2}{l}{$\mathrm{H}_{0}$ NOT accepted } & \multicolumn{2}{l}{$\mathrm{H}_{0}$ NOT accepted } \\
association & DEPENDENT & DEPENDENT & DEPENDE & $\mathrm{T}$ \\
\hline
\end{tabular}

Note: Q5: Duration Of Consumption, Q16: Retailer And Sale Force Attitude Towards Consumer Request, Q44: Consumption Probability

As illustrate in table 3 . The $p$ value of all assumption are under 0.05 , therefore, we conclude there is association between variables, the next step is the measure the strength of this association with the help of Gamma coefficient we measure this purpose.

1.a Gamma coefficient: in case of customer's satisfaction, there is a $55 \%$ percent of product and customer satisfaction in cosmetic product which is considered as strong association.

1.b Gamma coefficient:duration of consumption and customer buying decision concerning further consumption of that product could be influence as $6.3 \%$ which is considered as weak association.

1.c Gamma coefficient: influence of sales agents' behaviour on the consumer buying decision to keep on using the unique brand can be seen as $20 \%$.

\section{$\underline{\text { Part B }}$}

2.a Is there any significant relationship between customer's perception concerning promotional strategies and what he/she observes? (In other words; does the customer care only about the influencing factors?

The table 3 indicated the appealing promotional activities based on customer's perception and shows the various activities which is accomplished by the producers of cosmetic product, therefore the Following results could be extract and we summarized as follows;

As we can observed from table 4, 5, 6, we have ranked the various promotional activities from top to down with highest influence in Iranian market, it is really important to know these factors for Marketing manager of cosmetic produced who really interested in entering to Iranian market due to huge market existence.

Table 4 revelled that product test in advance of purchasing it is considered as vital a promotional strategy and more influential factor in compared to holding competitions with great prizes.

Table 4. Promotional technique ranking

\begin{tabular}{ll}
\hline Ranked frequency & Promotional technique \\
\hline 63 & test possibility in advance of purchase order \\
52 & holding competitions with great prizes \\
51 & discount for regular customers \\
37 & offering free product packages as samples \\
33 & discount for a specific purchase amount \\
15 & temporary discounts \\
\hline
\end{tabular}


Table 5. Promotional technique

\begin{tabular}{ll}
\hline Ranked frequency & Promotional technique \\
\hline 1 & products' promotion using phone calls \\
1 & offering purchase coupon \\
3 & promotional exhibition or demonstration \\
4 & sponsoring sports teams or advertisement in stadium \\
4 & promotional activities in special events \\
7 & advising advertisements \\
\hline
\end{tabular}

Table 6. Rank of promotional technique

\begin{tabular}{ll}
\hline Ranked frequency & Promotional technique \\
\hline 27 & promotional activities using popular characters \\
91 & suggestions made by a friend \\
\hline
\end{tabular}

2.b What is the influence of our company's performance with respect to each promotional activity based on customers' perception?

Table 7. Promotional activities based on customer perception

\begin{tabular}{|c|c|c|c|c|c|c|c|c|c|}
\hline \multirow{2}{*}{$\begin{array}{l}\text { Satisfaction } \\
\text { variables }\end{array}$} & \multirow[t]{2}{*}{ group } & \multirow[t]{2}{*}{ Category } & \multirow{2}{*}{$\begin{array}{l}\text { Test } \\
\text { proportion }\end{array}$} & \multicolumn{3}{|c|}{ Foreign shampoo } & \multicolumn{3}{|c|}{ Iranian shampoo } \\
\hline & & & & $\mathrm{N}$ & $\begin{array}{l}\text { Observed, } \\
\text { pro }\end{array}$ & $\begin{array}{l}\text { Exact } \\
\text {,sig }\end{array}$ & $\mathrm{N}$ & $\begin{array}{l}\text { Observed, } \\
\text { pro }\end{array}$ & $\begin{array}{l}\text { Exact, } \\
\text { sig }\end{array}$ \\
\hline Comparison with & Group1 & $<=3$ & .4 & 70 & .29 & & 63 & .32 & \\
\hline \multirow{2}{*}{ similar product } & Group2 & $>3$ & .4 & 169 & .71 & & 136 & .68 & \\
\hline & Total & & & 239 & 1.00 & .000 & 199 & 1.00 & .000 \\
\hline \multirow{3}{*}{ Consumer loyalty } & Group1 & $<=3$ & .4 & 98 & .4 & & 84 & .41 & \\
\hline & Group2 & $>3$ & .4 & 150 & .6 & & 119 & .59 & \\
\hline & Total & & & 248 & 1.00 & .000 & 203 & 1.00 & .000 \\
\hline \multirow[t]{3}{*}{ Rectifying needs } & Group1 & $<=3$ & .4 & 119 & .49 & & 103 & .57 & \\
\hline & Group2 & $>3$ & .4 & 122 & .51 & & 78 & .43 & \\
\hline & Total & & & 241 & 1.00 & .000 & 181 & 1.00 & .000 \\
\hline \multirow{6}{*}{$\begin{array}{l}\text { Impact of } \\
\text { promotion } \\
\text { satisfaction } \\
\text { Satisfaction about } \\
\text { quality }\end{array}$} & Group1 & $<=3$ & .4 & 62 & .27 & & 40 & .22 & \\
\hline & Group2 & $>3$ & .4 & 169 & .73 & & 143 & .78 & \\
\hline & Total & & & 231 & 1.00 & .000 & 183 & 1.00 & .000 \\
\hline & Group1 & $<=3$ & .4 & 50 & .2 & & 55 & .29 & \\
\hline & Group2 & $>3$ & .4 & 200 & .8 & & 135 & .71 & \\
\hline & Total & & & 250 & 1.00 & .000 & 190 & 1.00 & .000 \\
\hline \multirow{3}{*}{$\begin{array}{l}\text { Reliability } \\
\text { product }\end{array}$} & Group1 & $<=3$ & .4 & 79 & .31 & & 59 & .31 & \\
\hline & Group2 & $>3$ & .4 & 174 & .69 & & 132 & .69 & \\
\hline & Total & & & 253 & 1.00 & .000 & 191 & 1.00 & .000 \\
\hline \multirow{3}{*}{$\begin{array}{l}\text { Satisfaction about } \\
\text { price }\end{array}$} & Group1 & $<=3$ & .4 & 146 & .61 & & 92 & .5 & \\
\hline & Group2 & $>3$ & .4 & 94 & .39 & & 93 & .5 & \\
\hline & Total & & & 240 & 1.00 & .000 & 185 & 1.00 & .000 \\
\hline \multirow{3}{*}{$\begin{array}{l}\text { Satisfaction about } \\
\text { packaging }\end{array}$} & Group1 & $<=3$ & .4 & 111 & .46 & & 89 & .50 & \\
\hline & Group2 & $>3$ & .4 & 125 & .33 & & 90 & .50 & \\
\hline & Total & & & 236 & 1.00 & .000 & 179 & 1.00 & .000 \\
\hline Satisfaction about & Group1 & $<=3$ & .4 & 155 & .67 & & 135 & .81 & \\
\hline \multirow[t]{2}{*}{ CRM } & Group2 & $>3$ & .4 & 76 & .33 & & 31 & .19 & \\
\hline & Total & & & 231 & 1.00 & .000 & 166 & 1.00 & .000 \\
\hline \multirow{3}{*}{$\begin{array}{l}\text { Satisfaction about } \\
\text { distribution } \\
\text { channel }\end{array}$} & Group1 & $<=3$ & .4 & 119 & .5 & & 72 & .41 & \\
\hline & Group2 & $>3$ & .4 & 120 & .5 & & 104 & .59 & \\
\hline & Total & & & 239 & 1.00 & .000 & 176 & 1.00 & .000 \\
\hline \multirow{3}{*}{$\begin{array}{l}\text { Comparison with } \\
\text { other } \\
\text { brands(domestic } \\
\text { or foreign) }\end{array}$} & Group1 & $<=3$ & .4 & 118 & .49 & & 111 & .6 & \\
\hline & Group2 & $>3$ & .4 & 125 & .51 & & 74 & .4 & \\
\hline & Total & & & 243 & 1.00 & .000 & 185 & 1.00 & .000 \\
\hline \multirow{3}{*}{$\begin{array}{ll}\text { Probability } & \text { o } \\
\text { repurchasing } & \end{array}$} & Group1 & $<=3$ & .4 & 70 & .29 & & 80 & .41 & \\
\hline & Group2 & $>3$ & .4 & 175 & .71 & & 116 & .59 & \\
\hline & Total & & & 245 & 1.00 & .000 & 196 & 1.00 & .000 \\
\hline \multirow{3}{*}{$\begin{array}{l}\text { Overall } \\
\text { satisfaction }\end{array}$} & Group1 & $<=3$ & .4 & 5 & .02 & & 0 & .00 & \\
\hline & Group 2 & $>3$ & .4 & 259 & .98 & & 203 & 1.00 & \\
\hline & Total & & & 264 & 1.00 & .046 & 203 & 1.00 & 0.00 \\
\hline
\end{tabular}


The major factor influence on customer satisfaction and customer dissatisfaction bothin Iranian and foreign shampoos could be summarized as stated in the table 8 :

Table 8. Attributes caused satisfaction and dissatisfaction in domestic and foreign cosmetic products

\begin{tabular}{llll}
\hline Foreign & & Iranian & \\
\hline Satisfaction & level & Satisfaction & level \\
Quality & $80 \%$ & Quality & $71 \%$ \\
Genuine & $69 \%$ & Genuine & $69 \%$ \\
Package & $53 \%$ & Distribution channels & $59 \%$ \\
Meet the requirements & $51 \%$ & Price & $50 \%$ \\
Distribution channels & $50 \%$ & Package & $50 \%$ \\
Dissatisfaction & level & Dissatisfaction & level \\
Price & $39 \%$ & Meet the requirements & $43 \%$ \\
CRM & $33 \%$ & CRM & $19 \%$ \\
\hline
\end{tabular}

With respect to statistical inferential extract from table 8 , it is really interesting to know that in both Iranian and foreign shampoo concentrate more on quality, genuine with different percentage whereas, the price and CRM are major attribute for customer dissatisfaction in foreign shampoo an s Meet the requirement and CRM are essential factors for dissatisfied customer with Iranian shampoo consumption.

\section{Part $C$ :}

3.a Is there any association between company's website visitors and customer's satisfaction from the website?

3.b Is there any association between company site attractiveness and customers' satisfaction from company's website?

Table 9. Company site attractiveness and customer satisfaction

\begin{tabular}{lllll}
\hline & \multicolumn{2}{l}{ Hypothesis 3.a } & \multicolumn{2}{l}{ Hypothesis 3.b } \\
\hline variable & Q48 & Website attractiveness & Q48 & Website satisfaction \\
Chi-square & $172.337^{\mathrm{a}}$ & $108.692^{\mathrm{b}}$ & $172.337^{\mathrm{a}}$ & $109.546^{\mathrm{b}}$ \\
$\mathrm{df}$ & 5 & 9 & 5 & 28 \\
Asymp.sig & .000 & .000 & .000 & .000 \\
Test result & $\mathrm{H}_{0}$ NOT accepted & $\mathrm{H}_{0}$ NOT accepted \\
association & DEPENDENT & DEPENDENT \\
\hline
\end{tabular}

Note: Q48: number of visiting website

3.c As indicated in table 9, K-2 test has been applied in this case due to qualitative nature of data. Since all the $\mathrm{p}$ value is less than $<5 \%$ in both tests, there is a significant correlation between website attractiveness and rate of site visit, therefore more attempts are made to increase the attractivenessof website superficial features and other items, the more the possibility of visit rate would be, and accordingly purchase probability increases. On the other hand, high visit rate from website could be classified throughcustomer's satisfaction from e-buying and company's website. The Association between company's website visitors and customer's satisfaction from the website is calculated as $10 \%$ percent through Gamma Coefficient, whereasassociation between company`s site attractiveness and customers' satisfaction from company's website can be seen as $23 \%$.

\section{Part D: Critical Factors influence on Consumer Buying Behaviour and Attitudes towards Cosmetic} Product

4.a Duration of consumption

4.b How often they buy product

4.c How the product introduced to them

4.d Product's Just noticeable difference (JND) or threshold difference for increment prices 
4.e Discover consumer buying preferences in Iranian cosmetic market.

4.f Examining the point of purchase (POP) in Iranian market.

4.g the study of customer reaction towards their complains

Retailer and sale force attitude towards consumer request

Table 10. Critical factors influence on consumer buying behavior

\begin{tabular}{|c|c|c|c|}
\hline VARIABLE & Value & Frequency & Percent \\
\hline \multirow[t]{4}{*}{ 4.a)Duration of consumption } & Less than 6 month & 76 & $16.59 \%$ \\
\hline & 1-3 years & 174 & $38 \%$ \\
\hline & $3-5$ years & 76 & $16.59 \%$ \\
\hline & More than 5 years & 132 & $28.82 \%$ \\
\hline \multirow[t]{4}{*}{ 4.b)How often buy a product } & Every 4-6 month & 34 & $7.82 \%$ \\
\hline & Every 2-3 month & 201 & $46.45 \%$ \\
\hline & Every month & 106 & $23.50 \%$ \\
\hline & Every 2-3 weeks & 96 & $22.23 \%$ \\
\hline \multirow[t]{5}{*}{ 4.c)How the product introduced } & By friends & 150 & $34.18 \%$ \\
\hline & By media & 57 & $12.98 \%$ \\
\hline & By advertising & 93 & $21.18 \%$ \\
\hline & By Sales person & 85 & $19.36 \%$ \\
\hline & By physician & 54 & $12.30 \%$ \\
\hline \multirow{5}{*}{$\begin{array}{l}\text { 4.d)(JND) or difference threshold for } \\
\text { increment prices }\end{array}$} & $\% 5$ & 61 & $13.84 \%$ \\
\hline & $\% 10$ & 136 & $30.71 \%$ \\
\hline & $\% 15$ & 92 & $20.9 \%$ \\
\hline & $\% 20$ & 58 & $13.15 \%$ \\
\hline & $\% 25$ & 94 & $21.4 \%$ \\
\hline \multirow[t]{5}{*}{ 4.e)Most place for purchasing product } & Cosmetic stores & 57 & $13 \%$ \\
\hline & agencies & 53 & $12 \%$ \\
\hline & pharmacies & 169 & $38 \%$ \\
\hline & Chain store & 76 & $17 \%$ \\
\hline & Super market & 89 & $20 \%$ \\
\hline \multirow{4}{*}{$\begin{array}{l}\text { 4.f)point of purchase(pop) in Iranian } \\
\text { market }\end{array}$} & Order by telephone & 25 & $5.68 \%$ \\
\hline & Go to shopping center & 365 & $82.96 \%$ \\
\hline & Order by e-mail & 25 & $5.68 \%$ \\
\hline & Shopping through website & 25 & $5.68 \%$ \\
\hline \multirow[t]{6}{*}{$\begin{array}{l}\text { 4.g)customer reaction in order to their } \\
\text { complains }\end{array}$} & $\begin{array}{l}\text { I don't buy and tell others about the } \\
\text { product's disadvantage (negative } \\
\text { WOM) }\end{array}$ & 100 & $22.47 \%$ \\
\hline & $\begin{array}{l}\text { I don't buy and give up whom want } \\
\text { to buy }\end{array}$ & 36 & $8.09 \%$ \\
\hline & $\begin{array}{l}\text { I never buy the product again, but } \\
\text { don't say anything to others }\end{array}$ & 103 & $23.15 \%$ \\
\hline & $\begin{array}{l}\text { I won't lodge a complaint, because I } \\
\text { know that no one answer me }\end{array}$ & 69 & $15.51 \%$ \\
\hline & I will lodge a complaint by phone & 53 & $11.90 \%$ \\
\hline & I will lodge a complaint in person & 84 & $18.88 \%$ \\
\hline \multirow{5}{*}{$\begin{array}{l}\text { 4.h)Sales force attitude towards } \\
\text { consumer request }\end{array}$} & Very poor & 25 & $5.92 \%$ \\
\hline & poor & 38 & $9 \%$ \\
\hline & Barely acceptable & 186 & $44.09 \%$ \\
\hline & good & 131 & $31.04 \%$ \\
\hline & Very good & 42 & $9.95 \%$ \\
\hline
\end{tabular}


> Duration Of Consumption:duration of consumption for shampoo product among Iranian consumer are between 1 to 3 years and it is counted for $38 \%$ and more than 5 years as $28.82 \%$ among Iranian respondents that show the relative loyalty in Iranian consumer

How often buy a product:those customers with purchase frequency of 2 or 3 months account for $46.45 \%$ of total customers whereas $23.50 \%$ of customers are used to buy such products once in a month. Anyway, it is obvious that Product life cycle of shampoo products is regarded as short life time.

$>$ How the product introduced: as Iranian market expected, those product which sales through channel of friends' suggestions (WOM) can captured higher percentage in compared to other methods such as media, advertising and sales agent.

\section{$>$ Just Noticeable difference or difference threshold for increment prices:}

JND is introduced as discount level that cannot encourage the customer to purchase the product and it is different for various products, however $10 \%$ discount revealed to get the maximum share of $30.71 \%$. In addition other discount levels such as $25 \%$ and $15 \%$ had $21.4 \%$ and $20.9 \%$ acceptability respectively.

> Most places for purchasing product:drugstores, supermarkets and chain markets are introduced as placeswhich people hang around for buying shampoo products with $38 \%, 20 \%$ and $17 \%$ market sharecaptured respectively.

Point of purchase (pop) in Iranian market: among a variety of existing options for purchasing shampoo products, going to shopping centres as a purchase method has revealed maximum statistical rate $82.96 \%$ that indicates the traditional nature of purchase process embedded in common people and even educated ones.

$>$ customer reaction in order to their complains: As statistics inferential revealed, it is interesting to pinpoint that $18.88 \%$ of people are used to discuss their complaints when they encounter any problem however there are still lots of people (46.29\%) who are not willing to propose their objection and keep them as secret, therefore they keep the a negative WOM which is really harmful to the business.

$>$ Sales force attitude towards consumer request:in generalcustomers' satisfaction from selling agents of cosmetics and hygienic products in Iran has been estimated to be around $40.99 \%$ and most respondent has a moderate satisfaction by 44.0

4.1 Proposed Model

Table 11. Factor analysis for promotion techniques

\begin{tabular}{|c|c|c|}
\hline $\begin{array}{l}\text { Component 1: } 34.976 \% \\
\downarrow \text { persuasive ADV } \rightarrow \text { selective } \\
\text { demand }\end{array}$ & $\begin{array}{l}\text { Component } 2: 16.710 \% \\
\downarrow \text { Reminder ADV } \rightarrow \text { keep } \\
\text { consumer thinking about }\end{array}$ & $\begin{array}{l}\text { Component 3: } 12.191 \% \\
\downarrow \text { Informative ADV } \rightarrow \text { primary } \\
\text { demand }\end{array}$ \\
\hline $\begin{array}{ll}\mathrm{q}_{29} & \begin{array}{l}\text { discount for a specific } \\
\text { purchase amount }\end{array}\end{array}$ & $\begin{array}{ll}\mathrm{q}_{22} & \text { promotional activities in } \\
\text { special events }\end{array}$ & $\begin{array}{ll}\mathrm{q}_{40} & \text { information concerning } \\
& \text { manufacturing company }\end{array}$ \\
\hline $\begin{array}{ll}\mathrm{q}_{25} & \text { trial consumption } \\
\mathrm{q}_{30} & \begin{array}{l}\text { discount for regular } \\
\text { customers }\end{array} \\
\mathrm{q}_{27} & \text { price discount } \\
\mathrm{q}_{24} & \text { free sample packages } \\
\mathrm{q}_{32} & \text { coupon } \\
\mathrm{q}_{31} & \text { promotional exhibition } \\
\mathrm{q}_{26} & \text { competitions with great } \\
& \text { prizes }\end{array}$ & $\begin{array}{ll}\mathrm{q}_{21} & \text { sponsoring sports teams } \\
\mathrm{q}_{23} & \text { promotional activities using } \\
& \text { popular characters }\end{array}$ & $\begin{array}{ll}\mathrm{q}_{20} & \text { advising advertisements } \\
\mathrm{q}_{28} & \text { products promotion using phone } \\
& \text { calls }\end{array}$ \\
\hline
\end{tabular}

Table 11 discovered the three main categories for promotional activity (IMC) which mainly used by cosmetic producer or even cosmetic importer in Iranian market therefore we measure each component by some questions that mentioned in the table. 


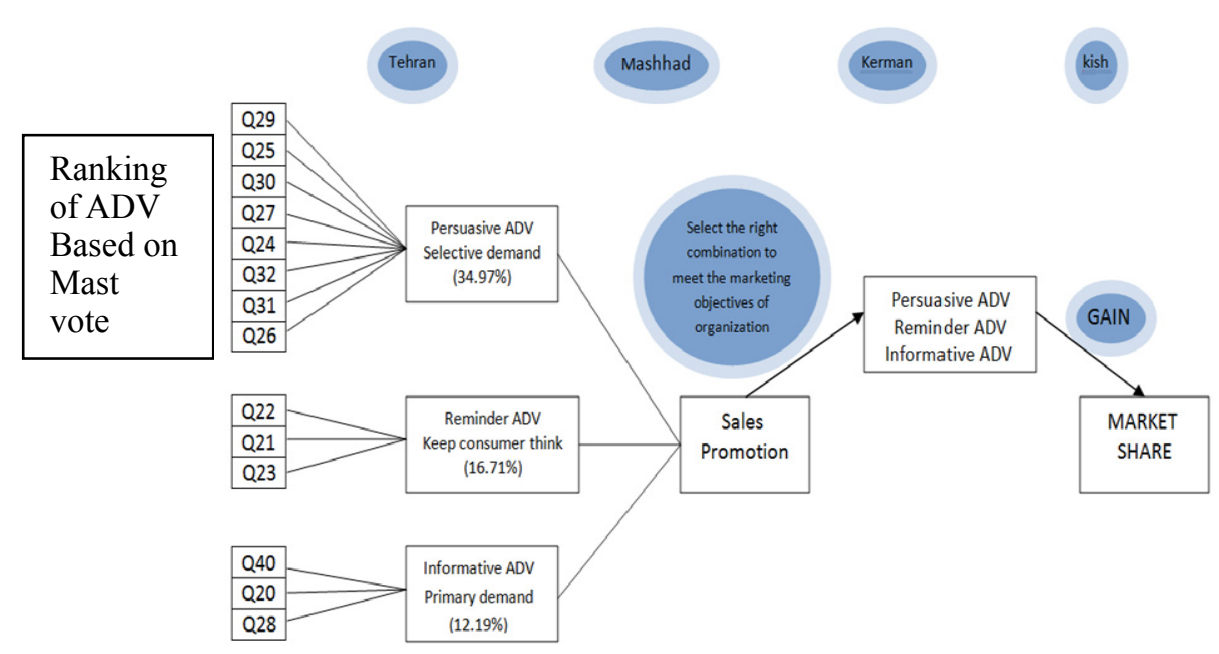

Figure 4. Proposed model for promotional technique (IMC) framework for Iranian cosmetic sector

In this research, a modelling framework is developed for Marketers and their companies to deal with promotional and advertising budget constraints, therefore selecting the precise promotional mix or integrated marketing communication (IMC) is valuable asset and equip companies to penetrate and develop the market share in Iranian market in this competitive market accordingly. In the present study, attempts have been made to find out the best combination of marketingstrategies to discover the best alternative choices available for cosmetic companies. Depict in figure 4 discussed the advertising has three main responsibilities to influence in consumer buying decision; therefore we can pinpoint it as 1) persuasive, 2) Reminder, 3) Informative which are considered as main influence in developing the market share y increasing the sale volume of concern product or service.Persuasive ADV, Reminder ADV and Informative ADV revealed the most influences which captured $35 \%, 17 \%$ and $12 \%$ respectively. Considering such conditions and a series of characteristics that would be mentioned further here in, one can ensure the organization that selection of a combination of these attributes could bring about influence rate of $63.87 \%$ overall.

\subsection{Segmentation of Domestic and Foreign Shampoo Product in Iranian Market}

\section{FOREIGN SHAMPOO}

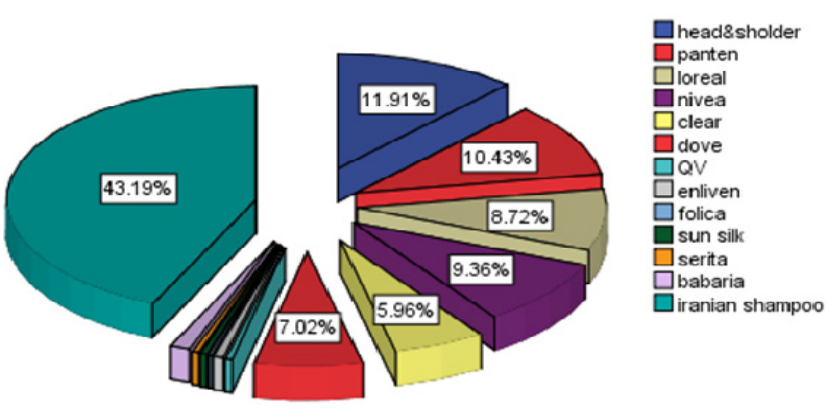

Figure 5. Foreign shampoo pie chart 


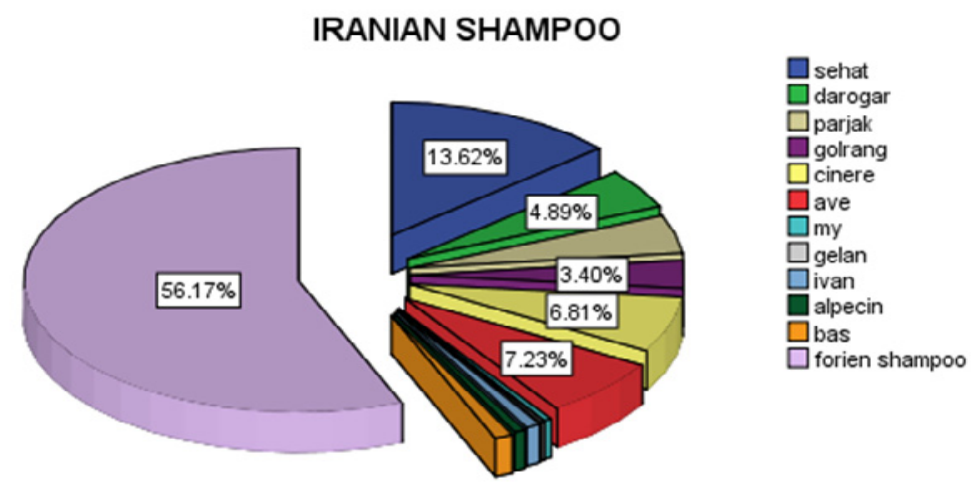

Figure 6. Iranian shampoo pie chart

As illustrated in the figures 5, 6 foreign shampoo products have $56.17 \%$ market share and the remaining market share belongs to $43.19 \%$ captured by Iranian branded shampoo. It is interesting to know the foreign brand such as Head \& Shoulders, Pantene and L'Oreal account for $31.06 \%$ out of $56.17 \%$ of foreign branded shampoo whereas the Sehat, Ave, Cinere grasp the $27.66 \%$ out of $43.19 \%$ among the domestic branded shampoo in current market share.

\subsection{Market Leaders \& Market Followers of Market}

Table 12. Penetration percentage rate of foreign \&Iranian shampoo

\begin{tabular}{llll}
\hline Foreign shampoo & Percent & Iranian shampoo & percent \\
\hline Head \& Sholders & $\mathbf{2 1 . 2}$ & Sehat & $\mathbf{3 0 . 5}$ \\
Panten & $\mathbf{1 8 . 6}$ & Darogar & $\mathbf{1 1 . 3}$ \\
Loreal & $\mathbf{1 5 . 2}$ & Parjak & 10.8 \\
Nivea & $\mathbf{1 6 . 7}$ & Golrang & 7.4 \\
Clear & 10.6 & Cinere & $\mathbf{1 5 . 8}$ \\
Dove & 12.5 & Ave & $\mathbf{1 6 . 7}$ \\
QV & 0.8 & My & 1.0 \\
Enliven & 1.1 & Gelan & 0.5 \\
Folica & 0.4 & Ivan & 2.0 \\
Sun silk & 0.8 & Alpecin & 1.5 \\
Babaria & 2.3 & Bas & 2.5 \\
Total & 100 & total & 100 \\
\hline
\end{tabular}

Table 13. Market leader \&market follower in Iran market

\begin{tabular}{ll}
\hline Iranian shampoo & Foreign shampoo \\
\hline Market leader & Market leader \\
Sehat & Head \& Sholder \\
Market follower & Market follower \\
Ave & Panten \\
Cinere & Neiva \\
Darogar & L'Oreal \\
\hline
\end{tabular}

As tables 12, 13 illustrated the market share of Iranian brand in the market of Iranian product and market share of foreign brand in the market of foreign product and with respect to table 13 we can classified Sehat and Head \& Sholder as a market leader in Iranian and foreign brands respectively, which brands (Ave, Cinere, Darogar) and (Panten, Neiva, L'Oreal) are market follower in Iran market 
Table 14. Summerize of chapter 4 hypothesis

\begin{tabular}{lll}
\hline \multicolumn{1}{c}{ Assumptions } & Accept & Reject \\
\hline Evaluation of consumption probability of a product and customer's satisfaction & $\checkmark$ & \\
Evaluation of consumption probability of a product and duration of consumption & $\checkmark$ \\
Evaluation of consumption probability of a product and agents' behaviour & $\checkmark$ & \\
Evaluation of Influence of 13 defines variables in customers' satisfaction & $\checkmark$ & \\
Evaluation of number of site visit and company's attractive nature & $\checkmark$ \\
Evaluation of number of site visit and customers' satisfaction & $\checkmark$ \\
\hline
\end{tabular}

\section{Conclusion and Suggestion}

Increasing trend of consumption of cosmetics and hygienic products among Iranian population support us the need of this study. The present study is one of the pioneer investigations in such field that deals with consumer buying behaviour and consumer attitudes towards domestic and foreign brand in this sector. Consumers make buying decisions every day and managers or marketers try to understand why, when, where and how consumers make decisions to buy a product. One complex duty of managers is to understand consumer buying behaviour in order to adapt their effort to consumers' interest with concentration more on product customization and culture among the Iranian community.

It is observed that the customer satisfaction, consumption duration and Sales agent behaviour has more priority in selection of brand in their consumer mind, furthermore this study indicated that that persuasive ADV, informative ADV and Reminder ADV are the most influential approaches which cosmetic companies should take into consideration while they are creating Advertising campaign.

Consumer proved that the following attributes are the most important and vital in cosmetic products:

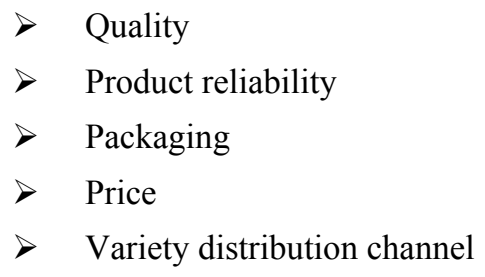

Empirical studies have shown that the Quality, product reliability (genuine), package and variety of distribution channels are the most influential factors for customers' satisfaction and consumer buying behaviour about the foreign cosmetic product (shampoos), while quality, product reliability (genuine), package, meet the requirements and variety of distribution channels are the most influential factors for customers' satisfaction and consumer buying behaviour in domestic Iranian product. one of the most advanced technology of promotional activates is just used of e-buying system in the world, whereas as it is reported that the lack of credible and reliable website, guarantee and warranty are the major barrier towards this technology in Iran and it didn't support us to shift from traditional buying behaviour toward internet buying behaviour. the penetration rate of domestic cosmetic product are captured by Sehat 30.5\%, Ave 16.7\%, Cinere 15.8\%, Darogar $11.3 \%$ whereas the penetration rate for foreign cosmetic products are captured by Head \& Shoulder 21.2\%, Panten $18.6 \%$, Nivea 16.7 and L'Oreal 15.2.

The present study identified that product test in advance of purchasing, holding competition with great prize and discount for regular customer are most effective promotional methods in Iranian cosmetic market. The study conclude that cosmetic company website attractiveness is one of the vital way of converting customer to satisfied customer in long term, it has the long way to accomplish in Iranian cosmetic sector and among the cosmetic producers and distributors.

In conclusion, we predict that best effective method of launching cosmetic product are classified through friend, media, print advertising and sales person in Iranian market both for domestic and foreign product.

\section{Managerial Implications}

The result from this study strongly suggest that, Sehat as one of the pioneer Iranian brand, accounted for $30.5 \%$ consumption of shampoo's in Iranian market. This company implemented the herbaceous ingredient in their products and this innovation technology converted Sehats to one of the major producer of shampoo among the other Iranian producers. According to the Iranian culture, herbaceous ingredient has a great value and people believe that this material has an ability to boost hair and has no detriments, therefore Sehat company can take 
advantage of herbaceous and construct the unique selling proposition in their advertising campaign and converted the sehat as market leader among the Iranian shampoo followed the Ave, Cinere, Darogar as Market follower in Iranian market. It is also observed that L'Oreal company implemented the localization by proper R\&D and innovation actives and respect to the culture as essential factor in foreign market by analyzing the Iranian market for foreign shampoo. Researcher also discovered that the Head \& Shoulder as Market leader followed by Panten, Neiva, L'Oreal as Market follower in Iranian market. More attention needs to be paid by the cosmetic companies to promotional mix, which is considered as one of the key elements of marketing strategy to capture the people from variety of cosmetic segments among the national and foreign brand in Iranian market.

\section{References}

Amadzadeh. (2009). The Scenario of Cosmetic product (Shampoo) in Iran. Retrieved from http://drahmadzadeh.parsiblog.com

DeBrohun, J. (2001). Power Dressing in Ancient Greece and Rome. Retrieved from http://www.hyperhistory.org

Godlove, I. H. (2011). The Earliest Peoples and their Colors.

Guthrie, M., Kim, H. S., \& Jung, J. (2008). The Effects of Facial Image and Cosmetic Usage on Perceptions of Brand Personality. Fashion Marketing and Management, 12(2), 64-181.

http://en.wikipedia.org

http://hitna.ir

http://www.entekhab.ir

Jobber. (2009). Principle and Practice of Marketing. MC Grawhill.

Joseph, F. H., \& Arthor, H. M. (2007). Research Method for Business. John Wiley \& Sons Ltd.

Kumar, S., Massie, C., \& Dumonceaux, M. D. (2006). Comparative Innovative Business Strategies of Major Players in Cosmetic Industry. Industrial Management \& Data Systems, 106(3), 285-306.

Leung, E. (2011). Young Iranian Consumers Have Their Say.

Miremadi, A. (2011). Gaining Competitive Advantages on E-CRM in Financial Institutions in Iran through B2B Model.

Momeni, A. F. (2009). Statistical Analysis with SPSS. Tehran.

Raouf, B. (2009). Malfunction 0f e-Buying among the Iranian People. Retrieved from http://itiran.com

Russel, R. (2006). Why Cosmetic Work. Oxford University Press.

The world Marketing News. (2011). The Iranians are Buying Behaviour Regarding Shampoo in Iran, MBA News.

Thomas, C. O., Guinn, C. T. A., \& Richard, J. S. (2009). Advertising \& Integrated Brand Promotion.

Xavier, D. P. (2011). Behavioural Economics And Customer Complains in Communication Markets. 


\section{Appendix}

Profile of Cosmetic Products among Iranian Respondents

\begin{tabular}{|c|c|c|}
\hline Profile & Frequency & Precent \\
\hline \multicolumn{3}{|l|}{ Gender } \\
\hline Male & 127 & $\% 27.0$ \\
\hline Female & 339 & $\% 72.1$ \\
\hline Missing & 4 & $\% 0.9$ \\
\hline Total & 470 & $\% 100.0$ \\
\hline \multicolumn{3}{|l|}{ Age } \\
\hline Under 18 & 29 & $\% 6.2$ \\
\hline $18-24$ & 223 & $\% 47.4$ \\
\hline $25-34$ & 134 & $\% 28.5$ \\
\hline $35-44$ & 46 & $\% 9.8$ \\
\hline More than 44 & 34 & $\% 7.2$ \\
\hline Missing & 4 & $\% 0.9$ \\
\hline Total & 470 & $\% 100.0$ \\
\hline \multicolumn{3}{|l|}{ Educational/level } \\
\hline Less than diploma & 35 & $\% 7.4$ \\
\hline Diploma & 152 & $\% 32.3$ \\
\hline Associate of art & 85 & $\% 18.1$ \\
\hline Bs & 137 & $\% 29.1$ \\
\hline Ms & 55 & $\% 11.7$ \\
\hline PHD & 1 & $\% 0.2$ \\
\hline Missing & 5 & $\% 1.1$ \\
\hline Total & 470 & $\% 100.0$ \\
\hline
\end{tabular}

